\title{
Finite Differences model for Ultra-fast Cooling in Hot Strip Mill
}

\author{
Xueqiang Wang ${ }^{1,2, a}$, Xudong $\mathrm{Li}^{3}$ and Guo Yuan ${ }^{1}$ \\ ${ }^{1}$ The State Key Laboratory of Rolling and Automation, Northeastern University, Shenyang 110819, \\ China. \\ 2 Shougang Qian'an Iron \& Steel Company, Qian'an 064400, China. \\ ${ }^{3}$ Shougang Research Institute of Technology, Beijing 100043, China. \\ awangxqsd@163.com
}

\begin{abstract}
The ultra-fast cooling (UFC) system can accomplish high efficiency and uniform cooling. To accomplish the high control precision of temperature by UFC, the differentiated mesh model was developed in the finite differences model. Based on the one-dimensional unsteady-state heat transfer model, the model for internal nodes and surface nodes of hot rolling strip were established. Combine the models above mentioned, the finite differences model was developed. The application results showed that the control precision of temperature was increased by $2 \%$.
\end{abstract}

Keywords: finite differences model, Ultra-fast cooling, hot strip mill, temperature control.

\section{Introduction}

The resource-saving, environment-friendly and low-cost steel products are the requirements for the fabrication industries. Ultra-fast cooling (UFC) is a significantly promising thermal management technique when implemented in the aforementioned steel production process and especially in hot strip rolling [1-3]. The thermo-metallurgical phase transformations of the steel take place during the cooling process on the run-out table (ROT). The microstructure and mechanical properties of steel are directly related to the cooling temperature [4-7].

The ultra-fast cooling (UFC) system can accomplish high efficiency cooling [8,9]. The calculating of the temperature deviation along the thickness direction becomes an effective way to improve the control precision of temperature. In this paper, the differentiated mesh model was developed in the finite differences model, and the model for internal nodes and surface nodes of hot rolling strip were established based on the one-dimensional unsteady-state heat transfer model. Combine the models above mentioned, the finite differences model was developed, and which was followed by the application results.

\section{Establish of Finite Differences Model}

\subsection{Differentiated Mesh Model.}

When the finite difference method is used to calculate the cooling temperature field after strip rolling, the solution precision is closely related to the sparsity degree of grid division and the selection of time step length. The denser the grid division, the shorter the time step, the higher the solution precision, while, the calculation amount will also increase exponentially.

In order to meet the demand of calculation precision and guarantee the timeliness of the mathematical model calculation cycle, the differentiated mesh model was established. We take the thickness of strip steel as unit1, the mesh number as 10, the schematic diagram of mesh model was shown in Fig. 1.

We can see that from Fig.1, the mesh close to the strip surface is dense, while the mesh close to the strip center is sparse, which not only ensures the accuracy of calculation, but also improves the efficiency of calculation 


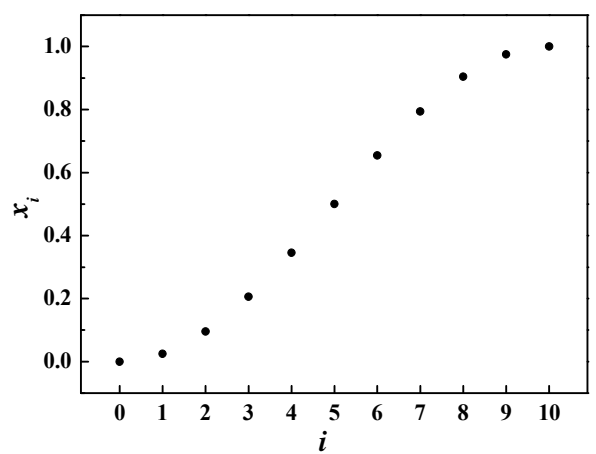

Fig. 1 Two or More References

\subsection{Model for Internal Nodes.}

The one-dimensional unsteady heat transfer differential equation without internal heat source is shown as follow [10].

$$
\frac{\mathrm{d} t}{\mathrm{~d} \tau}=\frac{\lambda}{\rho c} \frac{\mathrm{d}^{2} t}{\mathrm{~d} x^{2}}
$$

Equation (1) is applied to time $\mathrm{p}$ and node $\mathrm{i}$, the following equation can be obtained.

$$
\left(\frac{\mathrm{d} t}{\mathrm{~d} \tau}\right)_{i}^{p}=\frac{\lambda}{\rho c}\left(\frac{\mathrm{d}^{2} t}{\mathrm{~d} x^{2}}\right)_{i}^{p}
$$

In equation (1), the first-order adopt explicit and forward difference, the second-order adopt central difference, the following equation can be obtained from equation (2)

$$
\left(d_{i, i-1}+d_{i+1, i}\right) \cdot t_{i}^{p+1}=\frac{2 \Delta \tau \lambda}{\rho c}\left[\frac{t_{i-1}^{p}}{d_{i, i-1}}-\left(\frac{1}{d_{i, i-1}}+\frac{1}{d_{i+1, i}}-d_{i, i-1}-d_{i+1, i}\right) \cdot t_{i}^{p}+\frac{t_{i+1}^{p}}{d_{i+1, i}}\right]
$$

There are some abbreviated as follows

$$
F=\frac{\Delta \tau \lambda}{\rho c}, l_{\mathrm{n}, i}=d_{i+1, i}, l_{\mathrm{d}, i}=\frac{1}{d_{i+1, i}}
$$

And then, the equation ( 3 ) can be translated as follow.

$$
\left(l_{\mathrm{n}, i-1}+l_{\mathrm{n}, i}\right) \cdot t_{i}^{p+1}=2 F\left[l_{\mathrm{d}, i-1} t_{i-1}^{p}-\left(l_{\mathrm{d}, i-1}+l_{\mathrm{d}, i}-l_{\mathrm{n}, i-1}-l_{\mathrm{n}, i}\right) \cdot t_{i}^{p}+l_{\mathrm{d}, i} t_{i+1}^{p}\right]
$$

The model for the internal nodes can be obtained, and shown as follow.

$$
\begin{aligned}
& {\left[\begin{array}{ccccc}
? & & & \\
& l_{\mathrm{n}, 0}+l_{\mathrm{n}, 1} & & & \\
& & & \\
& & l_{\mathrm{n}, n-2}+l_{\mathrm{n}, n-1} & \\
& & & ?
\end{array}\right] \cdot\left[\begin{array}{c}
t_{0}^{p+1} \\
t_{1}^{p+1} \\
\mathrm{M} \\
t_{n-1}^{p+1} \\
t_{n}^{p+1}
\end{array}\right]=} \\
& {\left[\begin{array}{ccccc}
2 F l_{\mathrm{d}, 0} & 2 F\left(l_{\mathrm{d}, 0}+l_{\mathrm{d}, 1}-l_{\mathrm{n}, 0}-l_{\mathrm{n}, 1}\right) & 2 F l_{\mathrm{d}, 1} & \\
& 0 & \\
& 2 F l_{\mathrm{d}, n-2} & 2 F\left(l_{\mathrm{d}, n-1}+l_{\mathrm{d}, n-1}-l_{\mathrm{n}, n-2}-l_{\mathrm{n}, n-1}\right) & 2 F l_{\mathrm{d}, n-1} \\
?
\end{array}\right] \cdot\left[\begin{array}{c}
t_{0}^{p} \\
t_{1}^{p} \\
\mathrm{M} \\
t_{n-1}^{p} \\
t_{n}^{p}
\end{array}\right]}
\end{aligned}
$$

\subsection{Model for Surface Nodes.}

During the cooling process after rolling, the top and bottom surfaces of strip are cooled at the same time. According to the product and process requirements of different steel grade, the heat transfer status of the top and bottom surfaces of strip steel is often different. Therefore, the mathematical 
model calculates the heat transfer boundary conditions of top and bottom surfaces of strip steel respectively. As the heat transfer process of strip is complex and changeable, the other heat transfer forms are all reduced to convection heat transfer.

The third type of boundary condition is adopted for the determination of boundary conditions. Therefore, the coefficient of convection heat transfer and the cooling medium temperature are set as known. According to Newton's cooling law, the boundary condition of difference model is obtained and shown as follow.

$$
\begin{aligned}
& \mathrm{x}=0 \lambda \frac{\mathrm{d} t}{\mathrm{~d} x}=h_{\mathrm{m} 0}\left(t_{\mathrm{m} 0}-t_{0}\right) \\
& \mathrm{x}=\mathrm{d} \lambda \frac{\mathrm{d} t}{\mathrm{~d} x}=h_{\mathrm{mn}}\left(t_{\mathrm{mn}}-t_{n}\right)
\end{aligned}
$$

To solve the heat transfer at the boundary node of strip steel, the heat balance method is used, and the balance equation of the energy input and energy output of the nodes are established, which is shown as follow.

$$
\frac{\rho c d_{1,0}}{2} \cdot \frac{t_{0}^{p+1}-t_{0}^{p}}{\Delta \tau}=\lambda \frac{t_{1}^{p}-t_{0}^{p}}{d_{1,0}}+h_{\mathrm{m} 0}\left(t_{\mathrm{m} 0}-t_{0}^{p}\right)
$$

The model for top and bottom surface of strip can be obtained by equation (11), respectively. Combine the models of inter nodes and surface nodes, the finite differences model can be obtained as follow.

$$
\begin{aligned}
& {\left[\begin{array}{ccccc}
l_{\mathrm{n}, 0} & 2 F l_{\mathrm{d}, 0} & & & \\
& l_{\mathrm{n}, 0}+l_{\mathrm{n}, 1} & & & \\
& & \ddots & & \\
& & & & \\
& & & l_{\mathrm{n}, n-2}+l_{\mathrm{n}, n-1} & \\
& & & & l_{\mathrm{n}, n-1}
\end{array}\right] \cdot\left[\begin{array}{c}
t_{0}^{p+1} \\
t_{1}^{p+1} \\
\vdots \\
t_{n-1}^{p+1} \\
t_{n}^{p+1}
\end{array}\right]-\left[\begin{array}{c}
\frac{2 \Delta \tau h_{\mathrm{m} 0} t_{\mathrm{m} 0}}{\rho c} \\
0 \\
\\
\vdots \\
0 \\
0 \\
\frac{2 \Delta h_{\mathrm{m} n} t_{\mathrm{m} n}}{\rho c}
\end{array}\right]=} \\
& {\left[\begin{array}{ccccc}
-2 F l_{\mathrm{d}, 0}+l_{\mathrm{n}, 0}-\frac{2 \Delta \tau h_{\mathrm{m} 0}}{\rho c} & 2 F l_{\mathrm{d}, 0} & & & \\
2 F l_{\mathrm{d}, 0} & 2 F L_{1} & 2 F l_{\mathrm{d}, 1} & & \\
& \ddots & & \\
& & & & \\
& 2 F l_{\mathrm{d}, n-2} & 2 F L_{n-1} & 2 F l_{\mathrm{d}, n-1} \\
& & 2 F l_{\mathrm{d}, \mathrm{n}-1} & -2 F l_{\mathrm{d}, n-1}+l_{\mathrm{n}, n-1}-\frac{2 \Delta \tau h_{\mathrm{m} n}}{\rho c}
\end{array}\right] \cdot\left[\begin{array}{c}
t_{0}^{p} \\
t_{1}^{p} \\
\vdots \\
t_{n-1}^{p} \\
t_{n}^{p}
\end{array}\right]}
\end{aligned}
$$

The temperature at different time can be obtained by solving the above difference matrix by iterative method.

\section{Application}

The new developed model was successfully applied to a hot strip plant. Table 1 shows the control precision of temperature on the typical steel grade.

Table 1 Control Precision of Temperature

\begin{tabular}{cccc}
\hline \multirow{2}{*}{ Steel grade } & \multirow{2}{*}{ Statistical quantiles } & \multicolumn{2}{c}{ Control precision (\%) } \\
\cline { 3 - 4 } Q235B & 108 & 93.28 & Optimized \\
Q345B & 82 & 91.95 & 95.13 \\
SPHC & 96 & 92.46 & 93.42 \\
HP295 & 79 & 91.55 & 94.13 \\
\hline
\end{tabular}


It can be seen that from the Table 1, the control precision of temperature on different steel grades had been nearly improved by $2 \%$.

\section{Summary}

To accomplish the high control precision of temperature by UFC, the differentiated mesh model was developed in the finite differences model. Based on the one-dimensional unsteady-state heat transfer model, the model for internal nodes and surface nodes of hot rolling strip were established. Combine the models above mentioned, the finite differences model was developed. The application results showed that the control precision of temperature was increased by $2 \%$.

\section{References}

[1]. G. Yuan, Z. L. Li, H. J. Li, et al. Control and application of cooling path after rolling for hot strip based on ultra fast cooling, Journal Of Central South University. Vol. 20 (2013) No. 7, p. 18051811.

[2]. Q. Xie, B. X. Wang, Z. D. Wang, et al. The Effect of Jet Angle and Initial Plate Temperature during Jet Impingement Heat Transfer Process in Ultra-Fast Cooling Technology, Steel Research International. Vol. 86 (2015) No. 5, p. 489-494.

[3]. X. L. Chen, G. D. Wang, Y. Tian, et al. An on-line finite element temperature field model for plate ultra fast cooling process, Journal Of Iron And Steel Research International. Vol. 21 (2014) No. 5, p. 481-487.

[4]. B. Wang, Z. D. Wang, B. X. Wang, et al. The Relationship Between Microstructural Evolution and Mechanical Properties of Heavy Plate of Low-Mn Steel During Ultra Fast Cooling, Metallurgical And Materials Transactions a-Physical Metallurgy And Materials Science. Vol. 46A (2015) No. 7, p. 2834-2843.

[5]. J. Chen, M. Y. Lv, S. Tang, et al. Low-carbon bainite steel with high strength and toughness processed by recrystallization controlled rolling and ultra fast cooling (RCR plus UFC), Isij International. Vol. 54 (2014) No. 12, p. 2926-2932.

[6]. S. Tang, Z. Y. Liu, G. D. Wang, et al. Microstructural evolution and mechanical properties of high strength microalloyed steels: ultra fast cooling (UFC) versus accelerated cooling (ACC), Materials Science and Engineering A. Vol. 580 (2013) No. p. 257-265.

[7]. L. G. Peng, X. H. Liu, X. M. Zhao, et al. Mathematic modeling on flexible cooling system in hot strip mill, Journal of Central South University. Vol. 21 (2014) No. 1, p. 43-49.

[8]. Z. L. Li, H. J. Li, G. Yuan, et al. Research and application of ultra-fast cooling system and velocity controlled strategy for hot rolled strip, Steel Research International. Vol. 86 (2015) No. 5, p. 478-488.

[9]. L. Y. Jiang, C. J. Zhao, J. H. Shi, et al. Hot rolled strip re-reddening temperature changing law during ultra-fast cooling, Journal Of Iron And Steel Research International. Vol. 22 (2015) No. 8, p. 694-702.

[10]. Q. Xie, B. X. Wang, Z. D. Wang, et al. Heat Transfer Coefficient and Flow Characteristics of Hot Steel Plate Cooling by Multiple Inclined Impinging Jets, Isij International. Vol. 56 (2016) No. 12, p. 2236-2242. 